\title{
Biomaterial Scaffolds as Pre-metastatic Niche Mimics Systemically Alter the Primary Tumor and Tumor Microenvironment
}

\author{
Brian A. Aguado, Rachel M. Hartfield, Grace G. Bushnell, Joseph T. Decker, \\ Samira M. Azarin, Dhaval Nanavati, Matthew J. Schipma, Shreyas S. Rao, \\ Robert S. Oakes, Yining Zhang, Jacqueline S. Jeruss, and Lonnie D. Shea*
}

Primary tumor (PT) immune cells and pre-metastatic niche (PMN) sites are critical to metastasis. Recently, synthetic biomaterial scaffolds used as PMN mimics are shown to capture both immune and metastatic tumor cells. Herein, studies are performed to investigate whether the scaffold-mediated redirection of immune and tumor cells would alter the primary tumor microenvironment (TME). Transcriptomic analysis of PT cells from scaffold-implanted and mocksurgery mice identifies differentially regulated pathways relevant to invasion and metastasis progression. Transcriptomic differences are hypothesized to result from scaffold-mediated modulations of immune cell trafficking and phenotype in the TME. Culturing tumor cells with conditioned media generated from PT immune cells of scaffold-implanted mice decrease invasion in vitro more than two-fold relative to mock surgery controls and reduce activity of invasionpromoting transcription factors. Secretomic characterization of the conditioned media delineates interactions between immune cells in the TME and tumor cells, showing an increase in the pan-metastasis inhibitor decorin and a concomitant decrease in invasion-promoting chemokine (C-C motif) ligand 2 (CCL2) in scaffold-implanted mice. Flow cytometric and transcriptomic profiling of PT immune cells identify phenotypically distinct tumor-associated macrophages (TAMs) in scaffold-implanted mice, which may contribute to an invasionsuppressive TME. Taken together, this study demonstrates biomaterial scaffolds systemically influence metastatic progression through manipulation of the TME.

\section{Introduction}

During tumorigenesis, the primary tumor (PT) releases factors including cytokines and exosomes that modify not only the local tumor microenvironment (TME), but also immune cell populations at a systemic level to promote invasion and metastasis. ${ }^{[1,2]}$ Primary tumors are sites of chronic inflammation, where immune cells (indicated as $\mathrm{CD}^{4} 5^{+}$) such as inflammatory monocytes (indicated as $\mathrm{Ly} 6 \mathrm{C}^{+} \mathrm{F} 4 / 80^{-}$), macrophages (indicated as $\mathrm{F} 4 / 80^{+} \mathrm{CD} 11 \mathrm{~b}^{+}$), and dendritic cells (indicated as CD11 $\mathrm{c}^{+}$) are recruited and modulated phenotypically to promote tumor cell invasion and metastasis. ${ }^{[2]}$ Specifically, recruited tumorassociated macrophages (TAMs, indicated as $\mathrm{F} 4 / 80^{+} \mathrm{CD}_{11 \mathrm{~b}}{ }^{+} \mathrm{VCAM}^{+}$) and resident TAMs (indicated as $\mathrm{F} 4 / 80^{+} \mathrm{CD} 11 \mathrm{~b}^{+} \mathrm{VCAM}^{-}$) are known to temper $\mathrm{CD}^{+}$T-cell activity and recruit T-regulatory cells to suppress antitumor immunity. ${ }^{[3]}$ PTs also mobilize myeloid precursor cells in the bone marrow to traffic to sites such as the lungs,
Dr. B. A. Aguado

Department of Biomedical Engineering

Simpson Querrey Institute for BioNanotechnology

Northwestern University

Evanston, IL 60208, USA

Dr. R. M. Hartfield, G. G. Bushnell, Dr. J. T. Decker,

Dr. R. S. Oakes, Y. Zhang, Prof. L. D. Shea

Department of Biomedical Engineering

University of Michigan

Ann Arbor, MI 48105, USA

E-mail: Idshea@umich.edu

Prof. S. M. Azarin

Department of Chemical Engineering

and Materials Science

University of Minnesota

Minneapolis, MN 55455, USA

The ORCID identification number(s) for the author(s) of this article can be found under https://doi.org/10.1002/adhm.201700903.

DOI: 10.1002/adhm.201700903

\author{
Dr. D. Nanavati \\ Proteomics Core Facility \\ Northwestern University \\ Chicago, IL 60611, USA \\ Dr. M. J. Schipma \\ NUSeq Core Facility \\ Northwestern University \\ Chicago, IL 60611, USA \\ Prof. S. S. Rao \\ Department of Chemical and Biological Engineering \\ University of Alabama \\ Tuscaloosa, AL 35487, USA \\ Prof. J. S. Jeruss \\ Department of Surgery \\ University of Michigan \\ Ann Arbor, MI 48105, USA \\ Prof. L. D. Shea \\ Department of Chemical Engineering \\ University of Michigan \\ Ann Arbor, MI 48105, USA
}


liver, and brain, where they differentiate into myeloid-derived suppressor cells (MDSCs, indicated as $\mathrm{Gr} 1{ }^{\mathrm{hi}} \mathrm{CD} 11 \mathrm{~b}^{+} \mathrm{Ly} 6 \mathrm{C}^{-}$cells) that further prepare the "soil" of the organ microenvironment for tumor cell colonization. ${ }^{[4-7]}$ This conditioned site, known as the pre-metastatic niche (PMN), ${ }^{[8]}$ assists metastatic tumor cells in extravasation from the circulation and supports survival of the new metastatic colony until it "awakens" from a dormant state to become a secondary malignancy. ${ }^{[9]}$

More recently, biomaterial scaffolds have been used as engineered PMNs to intercept immune cells, leading to the capture of early metastatic cells at the implant site. ${ }^{[10-18]}$ The recruitment of metastatic cells at the implant is mediated in part by immune cells. All biomaterial implants have a foreign body response upon implantation, with initial recruitment of innate immune cells such as neutrophils, macrophages, and dendritic cells that release cytokines and chemokines at the scaffold and induce microenvironmental changes. ${ }^{[19,20]}$ These immune cell dynamics were recently investigated for scaffolds implanted into a healthy mouse, with inoculation of tumor cells after $30 \mathrm{~d}^{\left[{ }^{[16]}\right.}$ For transplantation into healthy mice, an initial dynamic immune population consisting mostly of macrophages and monocytes was observed, which subsequently stabilized after $14 \mathrm{~d}^{\left[{ }^{[16]}\right.}$ Following inoculation of tumor cells, the immune populations within the scaffold changed substantially. $\mathrm{Gr} 1{ }^{\text {hi }} \mathrm{CD} 11 \mathrm{~b}^{+} \mathrm{Ly} 6 \mathrm{C}^{-}$cells were notably absent from the scaffold of healthy mice and were $\approx 20 \%$ of leukocytes present at the scaffold in tumor-bearing mice. Moreover, mice implanted with scaffolds had a survival benefit over mock-surgery mice, with reduced metastatic tumor burden at the liver and brain and MDSC burden at the spleen and PT. Since ablation of $\mathrm{Gr}^{\mathrm{hi}} \mathrm{CD} 11 \mathrm{~b}^{+} \mathrm{Ly}_{6 \mathrm{C}}{ }^{-}$cells removed the survival benefit conferred by the scaffold, we hypothesize that the interception of immune cell types that condition the PMN (such as $\mathrm{Gr}^{\text {hi }}{ }^{\mathrm{C}} \mathrm{CD} 11 \mathrm{~b}^{+} \mathrm{Ly} 6 \mathrm{C}^{-}$ cells) is a mechanism whereby the scaffold influences disease progression.

Analogous to immune cells establishing PMNs in target organs, immune cells recruited to the PT participate in remodeling the proximal TME and impact subsequent tumor progression. In addition to interactions with local resident immune cells, the PT also mobilizes and recruits myeloid and inflammatory monocyte precursors. Within the TME, these differentiate, respectively, into $\mathrm{Gr} 1{ }^{\mathrm{hi}} \mathrm{CD} 11 \mathrm{~b}^{+} \mathrm{Ly} 6 \mathrm{C}^{-}$MDSCs and TAMs that repress anti-tumor immunity and support tumor invasion and metastasis. ${ }^{[7,21]}$ The TME is heterogeneous, and pathogenesis results from various changes in cell-extracellular matrix (ECM) interactions, paracrine signaling with surrounding tumor-supportive cells, changes in oxygen/nutrient supply, and biomechanical cues. ${ }^{[22]}$ Immune cells recruited to the PT contribute to the initiation of tumor cell epithelial-to-mesenchymal transition (EMT), motility, and eventual invasion. ${ }^{[2]}$ Immune cells also "prime" tumor cells for escape into the vasculature, thus increasing their chances of survival and colonization to a target organ site. ${ }^{[23]}$ Within the PT, various immune cell populations either promote or suppress tumor progression through direct contact with tumor cells or through secretion of chemokines and cytokines. ${ }^{[24,25]}$ Given that recruited immune cells in the TME influence tumor progression, it follows that systemic changes to the trafficking patterns of these immune cells would impact the TME and, consequently, the tumor.
In this paper, we postulate that biomaterial scaffolds, by modulating immune cell trafficking and phenotype, can influence the TME at a PT, resulting in inhibition of tumor progression. We hypothesize that alterations in immune cell trafficking induced by the scaffold may alter the phenotype of immune cells at the PT, which may contribute to the reduced disease burden observed in prior studies. ${ }^{[15,16]}$ Using an orthotopic mouse model of MDA-MB-231BR breast cancer, we implanted microporous poly(lactide-co-glycolide) (PLG) scaffolds in the intraperitoneal fat and characterized tumor and TME alterations. PTs were obtained from tumor-inoculated mice with and without scaffolds (termed scaffold and mock mice, respectively). We analyzed the transcriptomes of PT cells isolated from scaffold and mock mice and identified relevant signaling pathways associated with the gene expression profiles. From $\mathrm{CD}_{4} 5^{+}$immune cells isolated from the PT, we generated conditioned media, which modulated invasion of tumor cells in vitro. Secreted factors in these $\mathrm{CD}_{4} 5^{+}$cells and associated signaling pathways modulating invasion in the tumor cells were analyzed using a combination of secretomics and TRanscriptional Activity CEll aRray (TRACER) technologies. Finally, immune cell populations at the PT were analyzed by flow cytometry and gene expression profiles to determine the origin and phenotype of the immune cells in the absence or presence of a scaffold. Collectively, this work elucidates a role for engineered PMNs in modulating PT activity and suggests that systemic manipulation of immune cell dynamics and distribution may provide new insights and therapeutic avenues for metastatic breast cancer.

\section{Results}

\subsection{Transcriptomes Reveal Invasion-Associated Signaling Pathways Differentially Regulated in Scaffold Mice}

We hypothesized that the scaffold may impact the cells within the PT based on our prior observations of scaffold-mediated reduction in metastatic burden in vivo. ${ }^{[15,16]}$ MDA-MB231BR cells were harvested from the PT of mock and scaffold mice, and RNA sequencing (RNAseq) was used to analyze the transcriptome of the tumor cells (Figure 1A). A total of 29,157 genes were mapped to the reference genome from reads in both mock and scaffold cDNA samples. After comparing the reads per kilobase per million mapped (RPKM) read values, 892 genes were shown to be differentially expressed in tumor cells in response to the scaffold implant $(p<0.01)$. A volcano plot was generated to visualize the significant differences of each gene, as well as the log-fold change calculated from the average RPKM triplicate values from mock and scaffold PT cDNA samples (Figure 1B; Table S1, Supporting Information).

Up- and downregulated genes $(p<0.01$, false discovery rate $(\mathrm{FDR})<0.1)$ were analyzed using gene ontology $(\mathrm{GO})$ approaches to determine enriched pathways in Metascape as a strategy to obtain the most relevant up- and downregulated signaling pathways in response to the scaffold. Metascape identified 20 clusters of differentially regulated molecular functions among upregulated genes (Figure 1C) and 18 clusters among downregulated genes (Figure 1D). Downregulated enriched pathways and GO molecular functions traditionally associated 
A

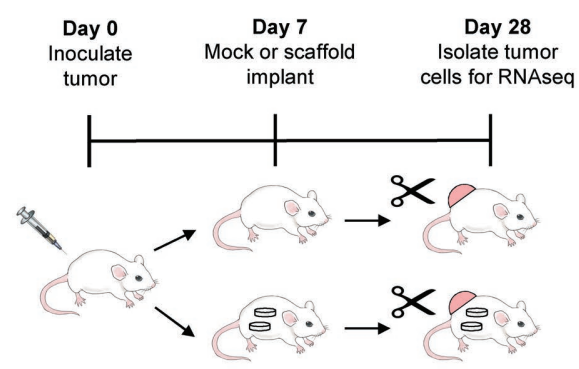

B

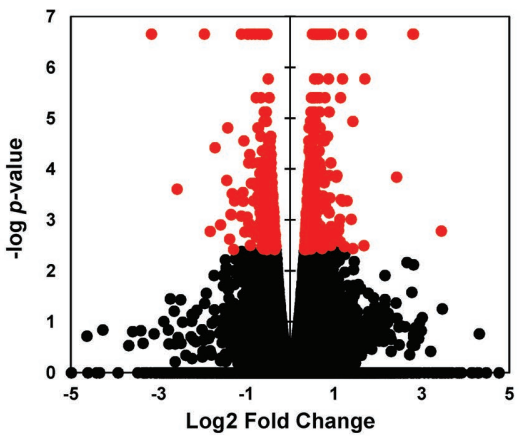

C

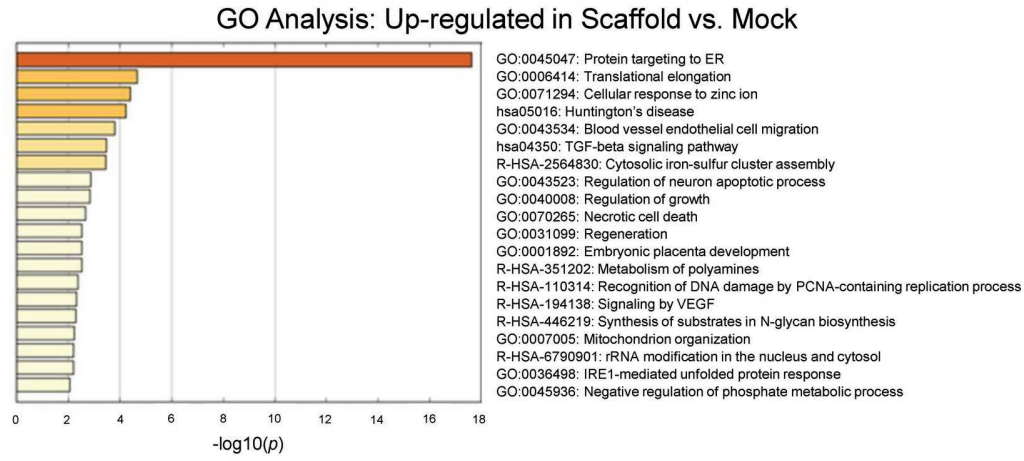

D

GO Analysis: Down-regulated in Scaffold vs. Mock

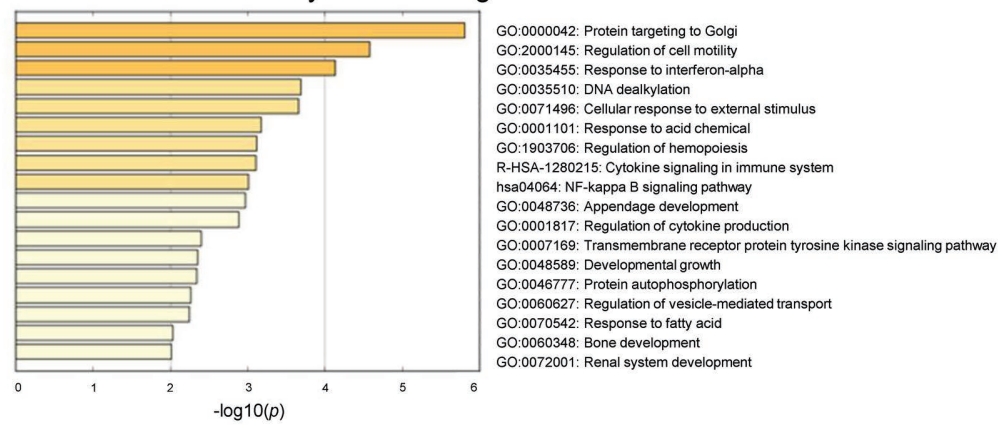

Figure 1. Transcriptomics analysis of primary tumor cells reveal differentially regulated genes and signaling pathways in response to PLG scaffold implants. A) Schematic of experimental design. B) Volcano plot showing 892 genes (in red) with most significantly altered gene expression of scaffold PT cells relative to mock PT cells $(n=3, p<0.01$, FDR $<0.1)$. A complete list of significantly altered genes is provided in Table S1 (Supporting Information). C,D) Metascape analysis of C) upregulated and D) downregulated genes $(p<0.01$, FDR $<0.1)$.

with cancer metastasis included regulation of cell motility, nuclear factor kappa-light-chain-enhancer of activated B cells $(\mathrm{NF} \kappa \mathrm{B})$ signaling, and cytokine signaling in the immune system (Figure 1D). A subset of these genes specific to $\mathrm{NF} \kappa \mathrm{B}$ signaling and cell motility (Table S2, Supporting Information) were validated by reverse transcription polymerase chain reaction (RT-PCR), with 5/7 following the same trends toward down- or upregulation as the RNAseq data (Table S3, Supporting Information).

\subsection{Conditioned Media from TME Immune Cells Alter Tumor Cell Invasion In Vitro}

We hypothesized that scaffold-induced changes in the tumor cell phenotype between scaffold and mock conditions may be mediated in part by immune cells in the TME. The contribution of the TME to tumor cell function was assessed in vitro following collection of conditioned media from $\mathrm{CD} 45^{+}$ immune cells present at the PT in mock and scaffold immunecompromised NSG and immune-competent BALB/c mice and subsequently used in tumor cell invasion assays in vitro (Figure 2A). Representative images are provided from transwell Matrigel invasion assays, showing invading MDA-MB-231 and 4T1 tumor cells cultured in unconditioned control, mock $\mathrm{CD}_{4} 5^{+}$conditioned, and scaffold $\mathrm{CD} 45^{+}$conditioned media (Figure 2B). For MDA-MB-231 cells in the invasion assay, a baseline of $250.0 \pm 14.6$ invading cells per image was observed using control medium. A significant increase in tumor cell invasion was observed for tumor cells cultured in mock CD45 ${ }^{+}$ conditioned media, with $356.6 \pm 20.5$ invading cells per image. Conversely, a marked decrease in tumor cell invasion was determined for cells cultured in scaffold $\mathrm{CD} 45^{+}$media compared to both control and mock CD45 ${ }^{+}$media, with $164.8 \pm 9.0$ invading cells per image (Figure 2C). Similarly, using 4T1 cells and the BALB/c transplant model, we observed a baseline of $792.2 \pm$ 15.1 cells per image in the control media, $1037.0 \pm 21.9$ cells in the mock CD45 ${ }^{+}$media, and $585.3 \pm 17.2$ cells in the scaffold $\mathrm{CD} 45^{+}$media (Figure 2D). Genes identified in our RNAseq analysis and associated with $\mathrm{NF} \kappa \mathrm{B}$ signaling and cell motility were also validated by RT-PCR in MDA-MB-231 cells treated with scaffold $\mathrm{CD}_{4} 5^{+}$media relative to mock $\mathrm{CD} 45^{+}$media, with $6 / 7$ genes displaying the same trends toward down- or upregulation (Table S4, Supporting Information). Collectively, the secreted factors present in conditioned media from scaffold $\mathrm{CD}_{4} 5^{+}$immune cells induce less invasion relative to the mock CD45 immune cells.

\subsection{Scaffolds Alter the Tumor-Associated CD45 ${ }^{+}$ Cell Secretome and Resulting Transcription Factor Activity of In Vitro MDA-MB-231 Cells}

We sought to identify secreted factors present in the mock and scaffold $\mathrm{CD}_{4} 5^{+}$media that might mediate the differential phenotypes observed with the invasion assay. CD $45^{+}$immune cells from mock and scaffold PTs were collected via fluorescence activated cell sorting (FACS) and cultured in vitro to generate 
A

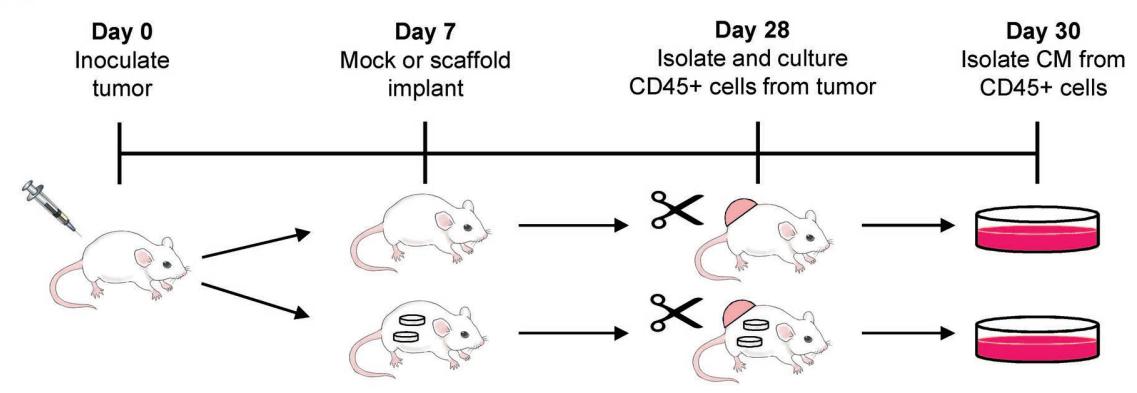

B
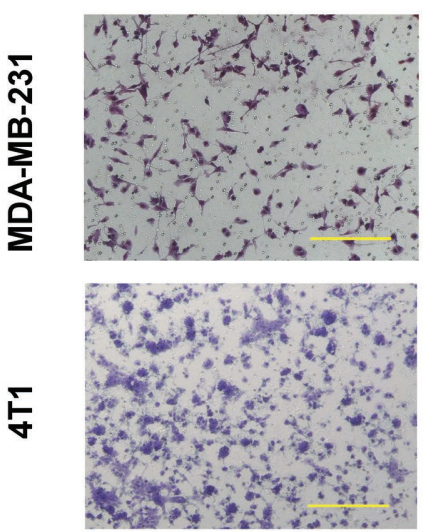

Mock
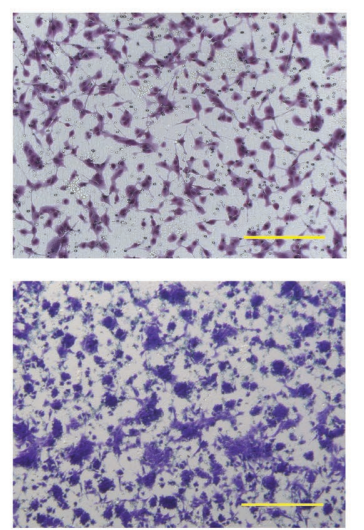

Scaffold

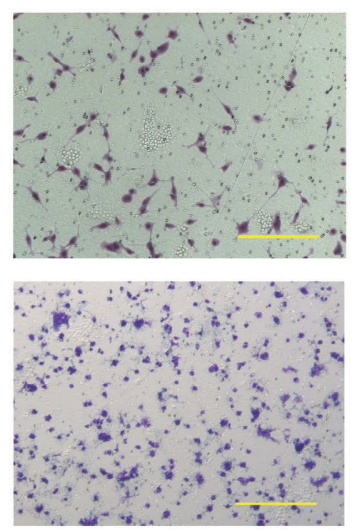

C
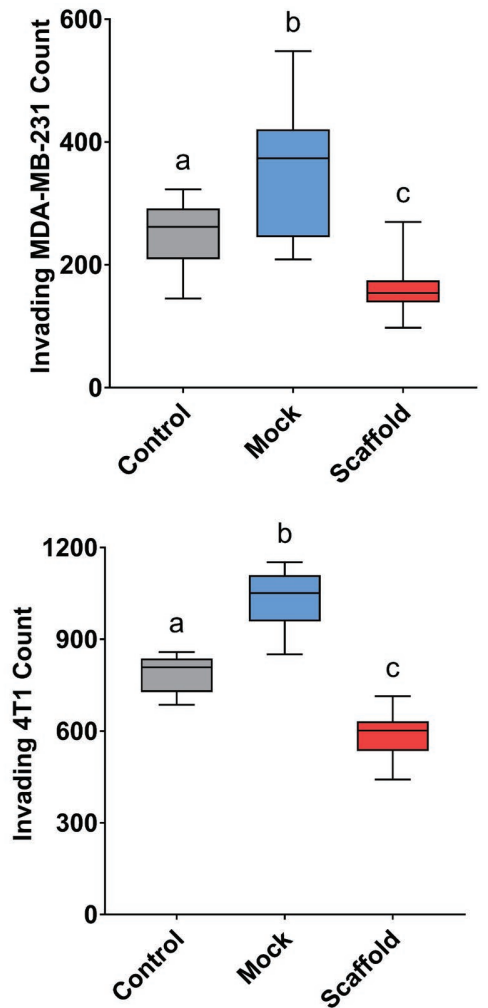

Figure 2. $C D 45^{+}$immune cell conditioned media from mock and scaffold mice alter MDA-MB-231 and 4T1 cell invasion. A) Schematic of experimental design. B) Representative bright-field images of invading tumor cells in various media. Scale bar on all images indicate $500 \mu \mathrm{m}$. C,D) Tumor cell invasion counts in Control, mock CD45 $5^{+}$conditioned media, and scaffold CD45 conditioned media $(n=12)$ for C) MDA-MB-231 and D) 4T1 tumor cells. Letters "a," "b," and "c" denote groups that are statistically distinct $(p<0.05)$ according to the one-way ANOVA with Bonferroni testing for multiple comparisons. Data are shown as box-and-whisker plots with minimum values, maximum values, and interquartile range.

conditioned media, which was subsequently analyzed using secretomics techniques. A total of 947 proteins were identified in both mock and scaffold $\mathrm{CD} 45^{+}$media, with at least one peptide spectral match (PSM) in each biological replicate. Of the 974 proteins identified, 161 proteins were identified as secreted factors. From this secreted factor pool, nine proteins had a $\log 2$ fold change greater than 1.5 in the mock CD $45^{+}$ media, and seven proteins had a $\log 2$ fold change greater than 1.5 in the scaffold CD45 ${ }^{+}$media (Figure $3 \mathrm{~A}$ ). A summary of the PSM values, the log2 fold changes, and the highlighted secreted factor targets in each media is provided (Table S5, Supporting Information). Using enzyme linked immunosorbent assays (ELISAs) to validate select secretomics results, we confirmed the increased abundance of CCL2 and decorin in mock and scaffold $\mathrm{CD}_{4} 5^{+}$media, respectively. CCL2 had a concentration of $241.8 \pm 24.3 \mathrm{pg} \mathrm{mL}^{-1}$ in mock CD $45^{+}$media compared to $108.4 \pm 18.7 \mathrm{pg} \mathrm{mL}^{-1}$ in scaffold $\mathrm{CD}^{2} 5^{+}$media (Figure $3 \mathrm{~B}$ ). Decorin had an increased concentration of $448.4 \pm 39.0 \mathrm{pg} \mathrm{mL}^{-1}$ in scaffold $\mathrm{CD}_{4} 5^{+}$media relative to $312.8 \pm 24.7 \mathrm{pg} \mathrm{mL}^{-1}$ in mock $\mathrm{CD} 45^{+}$media (Figure $3 \mathrm{C}$ ). These results suggest that the $\mathrm{CD}_{4} 5^{+}$conditioned media from scaffold mice have altered protein compositions that may contribute to modulating metastatic cell invasion.

We subsequently investigated the activity of multiple transcription factors (TFs) in response to the conditioned media, which reflect the signaling pathways stimulated by factors in the conditioned media. TF activity in MDA-MB-231 cells cultured in scaffold CD $45^{+}$versus mock CD $45^{+}$media was measured using TRACER. The transactivation profiles of $15 \mathrm{TF}$ reporter constructs over a period of $8 \mathrm{~h}$ were determined by normalizing TF activity of cells cultured in scaffold $\mathrm{CD}_{4} 5^{+}$media compared to mock $\mathrm{CD} 45^{+}$media (Figure S1, Supporting Information). Of the 15 reporters tested, $4 \mathrm{TF}$ reporters had significantly altered activity when cultured in scaffold $\mathrm{CD} 45^{+}$media (Figure 3D). One reporter, GATA1, had increased activity in scaffold $\mathrm{CD} 45^{+}$compared to mock $\mathrm{CD}_{4} 5^{+}$media. Three reporters had decreased activity in response to scaffold $\mathrm{CD}_{4} 5^{+}$media, including $\mathrm{NF} \kappa \mathrm{B}$, retinoic acid receptor (RAR), and serum response factor (SRF). The decrease in both NF $\kappa$ B and SRF activities would be consistent with partial antagonism of epidermal growth factor receptor (EGFR) and vascular endothelial growth factor receptor 2 (VEGFR2) by decorin. ${ }^{[26]}$ Moreover, we noted that 13 target genes of SRF and 23 target genes of $\mathrm{NF} \kappa \mathrm{B}$ were among the differentially regulated genes identified by RNAseq (Table S6, Supporting Information). Interestingly, only three genes of $\mathrm{SRF}$ and seven genes of NF $\kappa \mathrm{B}$ were downregulated; thus, the dynamic signaling of these transcription factors could not have been deduced by gene expression analysis alone. The four TF reporters with significantly altered activity have been previously reported as mediators of tumor cell motility and invasion. ${ }^{[27-31]}$ 
A

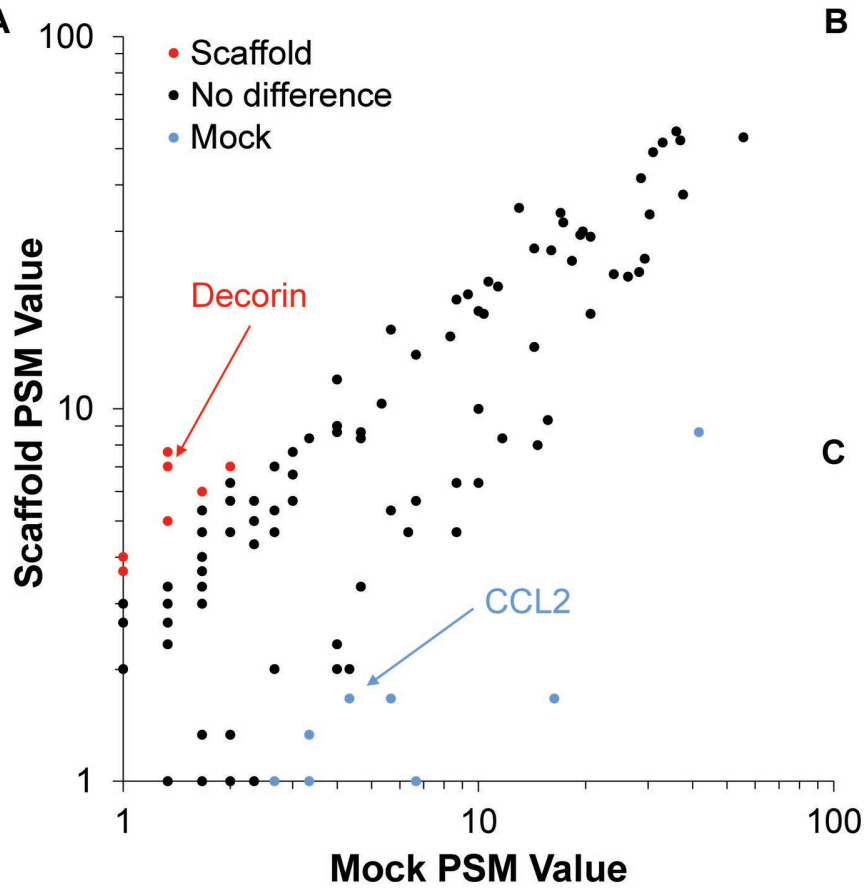

B
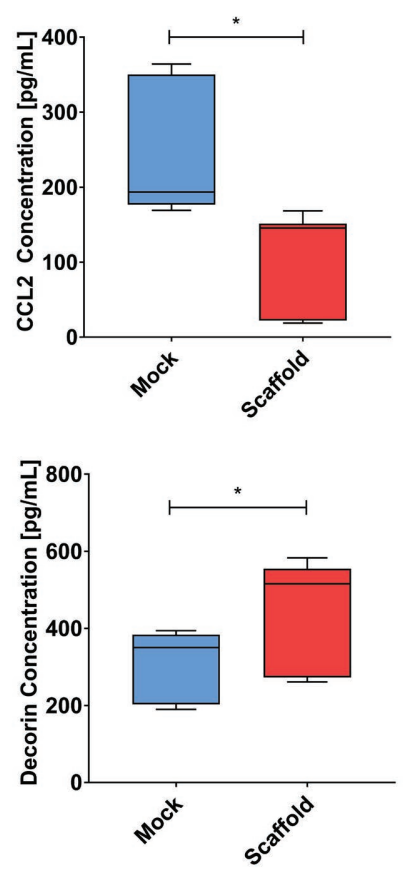

D

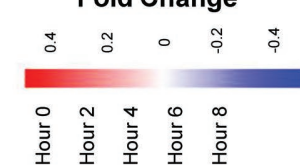

STAT3

STAT1

SRF

SP1

SMAD3

RAR

NFKB

NFAT

MEF1

HIF1

GATA1

FOX03A

ELK1

CRE

CMYC

Figure 3. Scaffold implants alter the $\mathrm{CD} 45^{+}$immune cell secretome, which changes transcription factor activity in MDA-MB-231 cells. A) Scatter plot showing the average peptide spectral match (PSM) values of 161 secreted factors present in both CD45 $5^{+}$mock and scaffold media $(n=3)$. The red points represent PSM values with a log2 fold change greater than 1.5 in the scaffold CD45 media, and the blue points represent PSM values with a log2 fold change greater than 1.5 in the mock CD45 media. A complete list of identified secreted factors is provided in Table S2 (Supporting Information). B) Concentration of CCL2 measured using ELISA in mock and scaffold CD45 media $(n=12)$, * $p<0.001$. C) Concentration of decorin measured using ELISA in mock and scaffold $C D 45^{+}$media $(n=12), * p<0.01$. Data are shown as box-and-whisker plots with minimum values, maximum values, and interquartile range. D) Heat map of normalized TF activity values for MDA-MB-231 cells cultured in scaffold CD45 conditioned media relative to mock $\mathrm{CD}_{4} 5^{+}$conditioned media over $8 \mathrm{~h}$. Significant changes in TF activity for at least one time point indicated in bold $(n=3$ arrays, $n=12$ total measurements per time point, $p<0.05)$.

\subsection{Scaffolds Alter Phenotype of Macrophage Subpopulations at the Primary Tumor}

Having established that the tumor and TME of scaffold and mock mice exhibit differences in transcriptome, invasive phenotype, secretome, and signaling, we investigated whether a difference in immune cell type, counts, or phenotype in the TME may provide mechanistic insight for these findings. Substantially more $\mathrm{F} 4 / 80^{+} \mathrm{CD} 11 \mathrm{~b}^{+} \mathrm{Ly} 6 \mathrm{C}^{-}$macrophages reside at the PT compared to other tissues, with $66.3 \pm 1.9 \%$ of leukocytes present compared to $0.14 \pm 0.04 \%$ leukocytes in the lung, $8.5 \pm 0.5 \%$ leukocytes in the spleen, and $7.3 \pm 0.8 \%$ at the scaffold (Figure $4 \mathrm{~A}$ ). We observed a modest reduction in the percent of $\mathrm{Gr} 1^{+} \mathrm{CD} 11 \mathrm{~b}^{+} \mathrm{Ly} 6 \mathrm{C}^{-}$ cells among CD45 $5^{+}$cells at the PT between scaffold and mock mice, with $15.0 \pm 1.6 \%$ for mock and $11.2 \pm 0.4 \%$ for scaffold (Figure 4B). On the other hand, no significant changes in other cell populations were observed, including $\mathrm{F} 4 / 80^{+} \mathrm{CD} 11 \mathrm{~b}^{+} \mathrm{Ly}_{6 \mathrm{C}}{ }^{-}$ macrophages $(68.5 \pm 0.9 \%$ for mock and $69.9 \pm 1.9 \%$ for scaffold), Ly6C $\mathrm{C}^{+} \mathrm{F} 4 / 80^{-}$monocytes $(6.1 \pm 0.5 \%$ for mock and $6.0 \pm 0.6 \%$ for scaffold), and CD11c ${ }^{+}$dendritic cells $(5.5 \pm 0.6 \%$ for mock and $5.9 \pm 0.6 \%$ for scaffold). In the BALB/c model, no significant changes were observed in innate and adaptive immune cell populations (Figure S2, Supporting Information).

With macrophages being the major cell type in the PT, we subsequently investigated the macrophage source and phenotype in the PT for mock and scaffold conditions. TAMs have been reported to consist of both tissue-resident macrophages and recruited macrophages that originate as $\mathrm{CCR}^{+}$monocyte precursors prior to infiltration of the tumor and subsequent differentiation into macrophages..$^{[3,32]}$ Recruited macrophages express the adhesion protein Vcam 1 and drive tumor invasion whereas resident macrophages are generally considered benign. ${ }^{[3]}$ We gated live $\mathrm{CD}^{4} 5^{+}$cells as $\mathrm{F} 4 / 80^{+} \mathrm{Vcam}^{+}$(denoted as $\mathrm{F}^{+} / \mathrm{V}^{+}$, recruited macrophages), $\mathrm{F} 4 / 80^{+} \mathrm{Vcam} 1^{-}\left(\mathrm{F}^{+} / \mathrm{V}^{-}\right.$, resident macrophages), or $\mathrm{F} 4 / 80^{-} \mathrm{Vcam}^{-}\left(\mathrm{F}^{-} \mathrm{V}^{-}\right.$, other leukocytes) and sorted these populations (Figure 4C). Relative quantities of each leukocyte population did not differ significantly between conditions, indicating that the recruitment of cells to the PT is similar for scaffold and mock mice (Figure 4D).

Macrophage populations were next transcriptionally analyzed to further validate phenotypic changes in recruited macrophage populations (Table S7, Supporting Information). $\mathrm{F}^{+} / \mathrm{V}^{+}$macrophages exhibited a significant increase in Lyve1, MafB, and CD163 and a concomitant decrease in MHCII and Ym1 relative to $\mathrm{F}^{+} / \mathrm{V}^{-}$macrophages across the board, consistent with their identity as a distinct, monocyte-derived macrophage subset. Comparing how these recruited $\mathrm{F}^{+} / \mathrm{V}^{+}$macrophages modified their transcriptome with respect to their resident macrophage counterparts, CCR2 and CCL7 were not significantly different in the mock TME but upregulated in the scaffold TME, whereas 

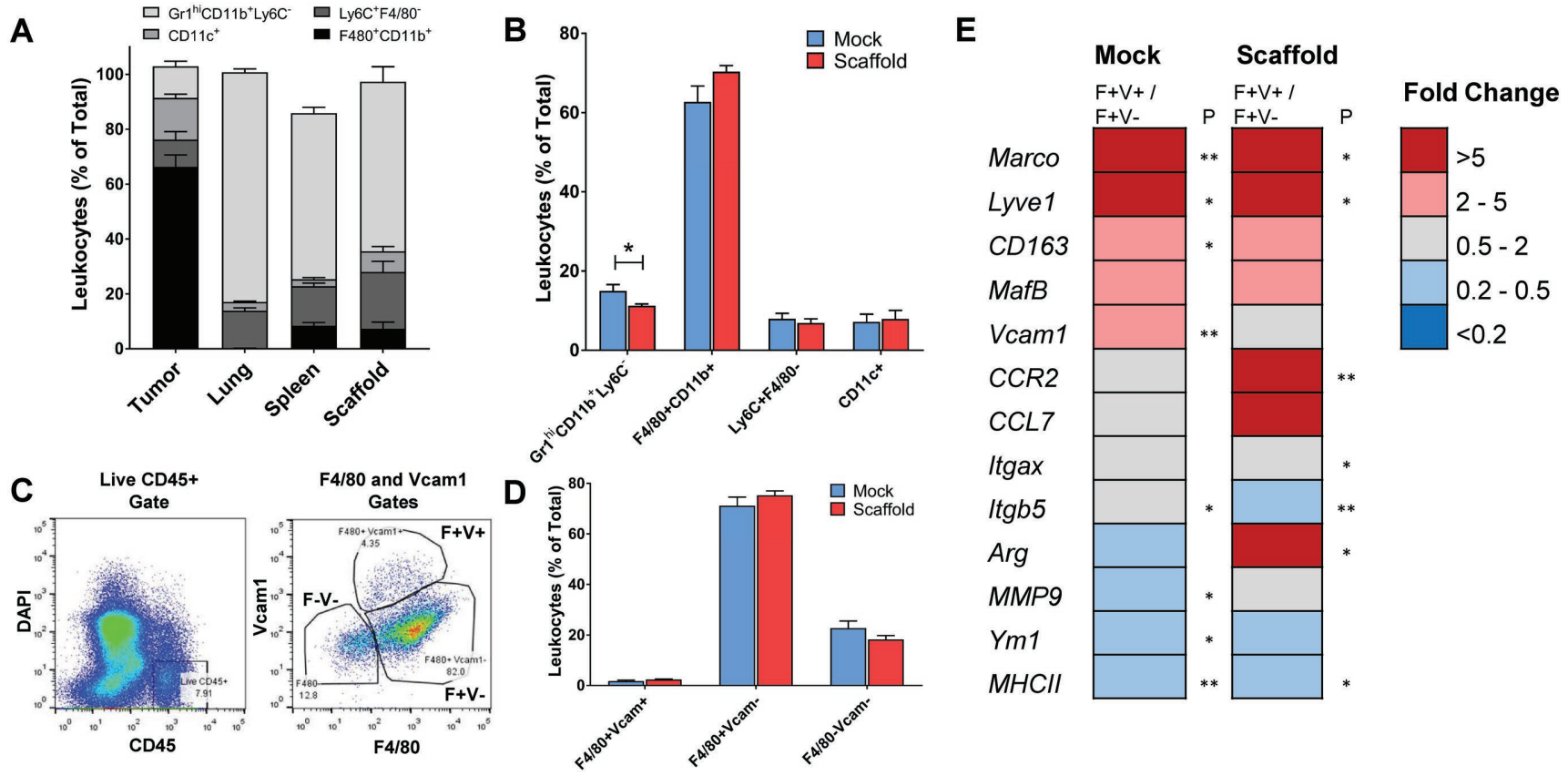

Figure 4. Characterization of immune cell populations and phenotypes at the primary tumor in response to scaffold implants. A) Percent of $C D 45^{+}$

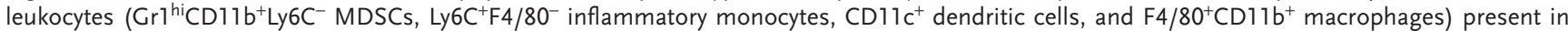
different tissues from PLG implanted mice $(n=5)$. B) Percent of CD45+ leukocytes present at the PT from mock surgery and PLG scaffold-implanted mice $(n=5, * p<0.05)$. C) Gating strategy for stratifying macrophage populations $\left(\mathrm{F} 4 / 80^{+} \mathrm{Vcam}^{+} \mathrm{C}^{+}\right.$(denoted as $\mathrm{F}^{+} / \mathrm{V}^{+}$, recruited macrophages), $\mathrm{F} 4 / 80^{+} \mathrm{Vcam}^{-}\left(\mathrm{F}^{+} / \mathrm{V}^{-}\right.$, resident macrophages), or $\mathrm{F} 4 / 80^{-} \mathrm{Vcam}^{-}\left(\mathrm{F}^{-} \mathrm{V}^{-}\right.$, other leukocytes)). D) Percent of leukocytes for each macrophage population $(n=5)$. Data are shown as mean \pm SEM. E) Fold change in invasion and metastasis associated genes in recruited versus resident TAM populations in mock and scaffold mice $(n=6)$. All genes shown at a confidence level of $90 \%$ or higher, with $* p<0.05$, $* * x<0.01$ according to the Student's $t$-test.

Vcam1 was more significantly upregulated in the mock condition than the scaffold condition (Figure 4E). Furthermore, in recruited $\mathrm{F}^{+} / \mathrm{V}^{+}$cells compared to $\mathrm{F}^{+} / \mathrm{V}^{-}$resident cells, arginase (Arg) was upregulated in the scaffold TME but downregulated in the mock TME, whereas $\operatorname{Itgb5}$ was downregulated in both conditions but more significantly in the scaffold condition and $M M P 9$ was downregulated in the mock condition but comparable in both populations in the scaffold condition. Taken together, these results suggest that $\mathrm{F}^{+} / \mathrm{V}^{+}$cells have a distinct functional phenotype in scaffold-implanted mice relative to mock mice at the PT, indicating that the scaffold may influence the phenotype of the immune cells within the PT.

\section{Discussion}

In this report, we demonstrate that implanted scaffolds affect systemic immune responses, with modulation of the secretomic and transcriptional profiles of immune cells in the TME, and, consequently, induce phenotypic changes in PT cells. Our prior work ${ }^{[13-15]}$ explored the concept of using a polymer scaffold to serve as a sink to capture disseminating tumor cells, thereby reducing tumor burden in host organs that are standard sites of breast cancer metastasis and improving host survival. ${ }^{[16]}$ Immune cells present at the scaffold partially mediate tumor cell attraction to the implant site. Our results suggest that scaffold-mediated redirection of immune cells also impacts the PT and the TME. In both immune-competent and immune-compromised models, secreted factors from PT immune cells in scaffold-implanted mice reduced tumor cell invasion in vitro relative to factors from control PT immune cells. The reduction in invasion observed using scaffold CD $45^{+}$ media was consistent with a distinct secretome, and reflects the transcriptomic differences that were observed in PT cells from scaffold-implanted relative to control mice.

We initially determined our biomaterial scaffolds influence both the in vivo tumor transcriptome and immune cell secretome. Without a scaffold, we identified CCL2 in the mock $\mathrm{CD} 45^{+}$conditioned media (among other factors), which may increase in vitro tumor cell invasion (Figure 2) and suggests enhanced invasion in vivo. CCL2 expressed in the tumor stroma recruits CCR2-expressing inflammatory monocytes, which are known to mediate tumor cell invasion and metastasis. ${ }^{[33]}$ As such, the unperturbed TME may contain factors that promote immunosuppression and ultimately promote tumor cell invasion and eventual metastasis. ${ }^{[33-35]}$ In response to the scaffold, Metascape analysis of the downregulated genes identified molecular functions and pathways suggestive of reduced invasive and metastatic capacity of the PT cells. RT-PCR analysis of a subset of genes identified in our RNAseq analysis and associated with $\mathrm{NF} \kappa \mathrm{B}$ signaling and cell motility showed modest fold changes in expression; however, our functional assays of cell migration and $\mathrm{NF} \kappa \mathrm{B}$ transcription factor activity confirmed downregulation of all these pathways, as the RNAseq pathway analysis suggested. Additionally, we identified decorin as a protein significantly more abundant in scaffold $\mathrm{CD} 45^{+}$media. Decorin, a 
leucine-rich proteoglycan present in the ECM, has been shown to reduce metastatic spreading of breast cancer through downregulation of EGFR activity. ${ }^{[36-38]}$ Further studies have demonstrated that decorin is known to sequester growth factors such as transforming growth factor beta (TGF $\beta$ ) and suppress prometastatic activity. ${ }^{[39]}$ Collectively, our transcriptomics analysis of the tumor cells and secretomics analysis of the CD45 cells suggest the TME is sensitive to systemic effects from the PLG scaffold implant and may influence tumor cell invasiveness.

Secreted factors identified in the scaffold TME stimulated distinct signaling patterns associated with inhibiting tumor cell invasion. Significant decreases were observed in TF activity for $\mathrm{NF} \kappa \mathrm{B}, \mathrm{RAR}$, and SRF reporters in tumor cells treated with scaffold $\mathrm{CD}_{4} 5^{+}$media using our TRACER arrays. Previous work demonstrates a significant role for NF $\kappa$ B in the inflammation response, as well as in regulating EMT and invasion processes in metastatic cells. NF $\mathrm{BB}$ signaling assists in blocking the degradation of Snail in metastatic cells during inflammationmediated metastasis, another transcription factor critical for initiating EMT. ${ }^{[40]}$ Likewise, RAR activity has been implicated in cholangiocarcinoma progression, demonstrating that increased RAR activity assists in tumor invasion. ${ }^{[11]}$ Previous work has also shown that depletion of SRF activity reduces MDA-MB231 cell invasion in vitro and reduces tumor cell colonization to the lung in vivo. ${ }^{[30]}$ Moreover, SRF is a downstream factor in extracellular signal-regulated kinase/mitogen-activated protein kinase (ERK/MAPK) signaling, which is repressed by decorin antagonizing VEGFR2. ${ }^{[42]}$ Previous work claims the NF $\kappa \mathrm{B}$ p65 subunit interacts with SRF to influence gene expression downstream of the serum response element (SRE) promoter, ${ }^{[43,44]}$ corroborating our observation that $\mathrm{NF} \kappa \mathrm{B}$ and SRF activity are linked and decrease in response to scaffold $\mathrm{CD} 45^{+}$media. Taken together, reduced NF $\kappa$ B, RAR, and SRF activities suggest tumor cells may have reduced invasive capacity in response to the scaffold. More broadly, our transcriptomic, secretomic, and TRACER assays provide complementary and convergent data on an overall network governing tumor cell invasion and the contributions of microenvironmental cues.

Our results suggest that changes in tumor cell phenotype are likely not due to fluctuations in immune cell recruitment to the PT. We initially hypothesized that the implanted scaffold would influence $\mathrm{Gr} 1{ }^{\text {hi }} \mathrm{CD} 11 \mathrm{~b}^{+} \mathrm{Ly} 6 \mathrm{C}^{-}$cell trafficking at the $\mathrm{PT}$, given the scaffold's ability to attract $\mathrm{Gr} 1{ }^{\text {hi }} \mathrm{CD} 11 \mathrm{~b}^{+} \mathrm{Ly}_{6} \mathrm{C}^{-}$and tumor cells away from target organ sites. ${ }^{[16]}$ Additionally, given the observed decrease in CCL2 in the scaffold CD $45^{+}$secretome, we also expected lower counts of inflammatory monocytes ${ }^{[33]}$ and a lower number of $\mathrm{Vcam}^{+}$macrophages in the scaffold PT, as they derive from $\mathrm{CCR}^{+}$monocytes. ${ }^{[3]}$ Given the minor changes in immune cell trafficking, coupled with the high abundance of $\mathrm{F} 480^{+} \mathrm{CD} 11 \mathrm{~b}^{+}$macrophages at the PT relative to other cell types, we sought to evaluate potential effects of the scaffold implant on TAM phenotype. TAMs at the PT have been implicated in modulating metastatic disease outcome and are also known to assist in metastatic cell invasion. ${ }^{[45-47]}$ Moreover, the subset of macrophages that are associated with promoting tumor cell invasion is the subset that derives from CCR2 ${ }^{+}$inflammatory monocytes recruited to the TME in response to cues sent out by the tumor. ${ }^{[3]}$ Given the role of TAMs in mediating PT cell invasion and the relatively high abundance of macrophages in PTs, we suspected that changes in TAM phenotype may be responsible for alterations in the TME and PT cells due to the scaffold implant.

Our results demonstrate that the scaffold-influenced TME altered the phenotype of recruited TAMs relative to the TME in mock surgery mice. We identified a subset of $\mathrm{F} 4 / 80^{+} \mathrm{Vcam} 1^{+}$ TAMs that featured an increase in gene expression of Lyve1, $M a f B$, and $C D 163$. MafB is a transcription factor that governs macrophage differentiation from monocytic or myeloid precursors, whereas CD163 confirms the monocytic origin and Lyve1 denotes these macrophages as TAMs. ${ }^{[32]}$ Rather than a decrease in the percentage of $\mathrm{F} 4 / 80^{+} \mathrm{Vcam} 1^{+}$recruited macrophages, we observed a different phenotype marked by higher relative expression levels of CCR2 and CCR2-binding CCL7, indicating reduced retention of the recruited TAMs. ${ }^{[48]}$ Additionally, the observed decrease in Ym1 expression would be consistent with the observations that $\mathrm{F} 4 / 80^{+} \mathrm{Vcam} 1^{+}$recruited macrophages are not of the alternatively activated phenotype. ${ }^{[3]}$ Others have observed $\mathrm{MHCII}^{\mathrm{hi}}$ and $\mathrm{MHCII}{ }^{\mathrm{lo}}$ macrophages in tumors and deduced that they represented different macrophage subsets. $^{[32]}$ Furthermore, our results suggest that TAMs from scaffold-implanted mice were less adhesive (decreased Itgb5 and Vcam1), suppressed inflammation (increased arginase), and enhanced vascular leakiness at the tumor (relatively higher MMP9). Changes in the transcriptomic profile of recruited TAMs may be attributed to the presence of a distal biomaterial scaffold and correlated with an altered TME secretome and diminished tumor cell invasion.

\section{Conclusion}

In summary, our work suggests that implantation of a biomaterial scaffold can have a systemic impact on immune cell phenotype, which was demonstrated through an engineered PMN mimic distally modulating the PT and TME. We suggest our PMN mimics can be utilized to evaluate interactions between the primary tumor, immune cells, and PMNs. ${ }^{[14]}$ Our study focused on the innate immune cells, though the potential remains that the adaptive immune response may also be influenced. In addition to manipulating immune cell phenotypes and the associated secretome, the scaffold may also alter other components of the tumor stroma, including cancer associated fibroblast phenotype and ECM composition. Additionally, PMN mimics may serve as "oncomaterials" for their potential clinical applications, ${ }^{[17]}$ which is based on results in mice that indicate the ability for early detection of metastatic disease $\mathrm{e}^{[15]}$ and reducing tumor burden. ${ }^{[16,18]}$ Future work may entail monitoring the trafficking of immune cells influenced by the tumor and scaffold in real time for precision medicine applications. ${ }^{[49]}$ Recent approaches in monitoring the immune response at implanted scaffolds in vivo using intravital imaging may be useful for determining immune cell trafficking over time at both the implant and tumor. ${ }^{[50]}$ Real-time evaluation of the immune response may further establish that the scaffold modulates the TME, and determine whether the scaffold's alteration of the TME can be leveraged to counter tumor progression in vivo. Collectively, our current results suggest that PLG scaffolds have an active role in modulating tumor burden and may provide a foundation for developing an effective implantable therapeutic tool. 


\section{Experimental Section}

Tumor Inoculation: Animal studies were performed in accordance with institutional guidelines and protocols approved by the Northwestern University Institutional Animal Care and Use Committee. Tumor inoculation was performed by injecting $2 \times 10^{6}$ tdTomato $^{+}$MDA-MB$231 \mathrm{BR}$ or $4 \mathrm{Tl}$ cells in a volume of $50 \mu \mathrm{L}$ phosphate buffered saline (PBS) (Life Technologies) into the number four right mammary fat pads of female NSG or BALB/c mice. ${ }^{[15,16]}$ Mice were purchased from The Jackson Laboratory or bred in house.

Scaffold Fabrication and Implantation: PLG scaffolds were fabricated as previously described. ${ }^{[15]}$ Briefly, microspheres were prepared by emulsifying a $6 \%$ solution of PLG (Lakeshore Biomaterials; 75:25 lactide:glycolide, inherent viscosity $=0.76 \mathrm{dL} \mathrm{g}^{-1}$ ) in dicholoromethane in $1 \%$ poly(vinyl alcohol) (PVA). Microspheres were washed four times with deionized water to remove residual PVA and lyophilized overnight. Next, microspheres were mixed with $250-425 \mu \mathrm{m}$ salt particles in a 30:1 ratio and pressed in a steel die at 1500 psi. The scaffolds were then gasfoamed, and salt particles were removed by washing in water for $90 \mathrm{~min}$. Scaffolds were sterilized with $70 \%$ ethanol and rinsed with water before drying. Scaffolds were implanted in the intraperitoneal fat pads $7 \mathrm{~d}$ posttumor inoculation. Mock surgeries were performed by extracting and reinserting the fat pads back into the abdomen without implants.

Primary Tumor Immune Flow Cytometry: For analysis of leukocyte populations, tumors were harvested, minced, and treated with a $1 \times$ triple enzyme mix $\left(10 \mathrm{mg} \mathrm{mL}^{-1}\right.$ collagenase IV, $1 \mathrm{mg} \mathrm{mL}^{-1}$ hyaluronidase, and 200 units $\mathrm{mL}^{-1}$ of DNAse in Hank's balanced salt solution) or $1 \times$ Liberase TM (Roche). Triple-enzyme-treated minced tissue was incubated for $1 \mathrm{~h}$, and centrifuged at $50 \times \mathrm{g}$ to remove undigested tissue. The supernatant was centrifuged at $500 \times g$ to obtain a suspension of PT cells. Liberase -treated tissue was incubated for $20 \mathrm{~min}$ at $37^{\circ} \mathrm{C}$ and then neutralized with $0.125 \mathrm{M}$ ethylenediaminetetraacetic acid (EDTA) and mashed through a $70 \mu \mathrm{m}$ cell sieve. Cells were blocked with anti-CD16/32 (1:50, Biolegend) and stained for viability using blue fixable UV dead cell stain kit (Life Technologies). Cells were then stained with AlexaFluor 700-conjugated anti-CD45 (30- F11, 1:125; Biolegend), Pacific Blue-conjugated anti-Gr1 (RB6-8C5, 1:70; Biolegend), APC Cy7conjugated anti-Ly-6C (HK1.4, 1:70; Biolegend), PE Cy7-conjugated antiF4/80 (BM8, 1:70; Biolegend), AlexaFluor 647-conjugated anti-CCR7 (4B12, 1:25; Biolegend), AlexaFluor 488-conjugated anti-CD206 (15-2, 1:50; Biolegend), and V500 AmCyan-conjugated anti-CD11b (M1/70, 1:70; eBioscience). Samples were analyzed using an LSR II flow cytometer (BDIS). Flow output data were gated and quantified using Flow)o software (Tree Star). Plotting and Student $t$-test statistical analysis were performed using GraphPad Prism.

Macrophage Subset Sorting: Single cell suspensions of tumor cells were blocked with anti-CD16/32 (1:50, Biolegend) and stained for viability with 4',6-diamidino-2-phenylindole (DAPI). Cells were then stained with AlexaFluor 700-conjugated anti-CD45 (30- F11, 1:125; Biolegend), PE Cy7-conjugated anti-F4/80 (BM8, 1:70; Biolegend), and PerCP-Cy5.5conjugated anti-Vcam1 (429, 1:125; Biolegend). Live leukocytes were collected using $\mathrm{DAPI}^{-}$and $\mathrm{CD} 45^{+}$gates, and then further separated into $\mathrm{F} 4 / 80^{-} \mathrm{Vcaml}^{-}, \mathrm{F} 4 / 80^{+} \mathrm{Vcaml}^{-}$, and $\mathrm{F} 4 / 80^{+} \mathrm{Vcaml}^{+}$subsets. Samples were analyzed using an LSR II flow cytometer (BDIS) and collected in TRIzol reagent (Invitrogen) for subsequent transcriptional analysis.

Live $\mathrm{CD}_{4} 5^{+}$and $t d \mathrm{Tomato}^{+}$Sorting: For live sorting, single cell suspensions of tumor cells were blocked with anti-CD16/32 (1:50, Biolegend) and stained for viability using blue fixable UV dead cell stain kit (Life Technologies). Cells were then stained with AlexaFluor 700-conjugated anti-CD45 (30-F11, 1:125; Biolegend) and PE Cy7conjugated anti-F4/80 (BM8, 1:70; Biolegend). For CD45+ leukocyte collection, single color controls were used to gate BlueFixable ${ }^{-} \mathrm{CD} 45^{+}$ cells. Live tumor cells were collected using BlueFixable ${ }^{-}$and tdTomato $^{+}$ gates. Live cells were collected in Roswell Park Memorial Institute (RPMI) 1640 media supplemented with 50\% fetal bovine serum (FBS) and $1 \%$ penicillin-streptomycin

$\mathrm{CD} 45^{+}$Conditioned Media Preparation: For large batches of $\mathrm{CD}^{+} 5^{+}$ media, tumor cells were stained with magnetic CD45 $5^{+}$beads (Miltenyi
Biotech) and separated using magnetic activated cell sorting (MACS) per the manufacturer's specifications. Briefly, cells were counted and incubated with the $\mathrm{CD} 45^{+}$magnetic beads for $10 \mathrm{~min}$. Cells were washed with MACS buffer and resuspended at a concentration of no more than $10^{8}$ labeled cells per column. CD $45^{+}$cells were collected from the column and resuspended at a concentration of $10^{6}$ cells $\mathrm{mL}^{-1}$ of serumfree RPMI. Cells were cultured for $48 \mathrm{~h}$ to condition the media. Media were collected, passed through a $0.22 \mu \mathrm{m}$ filter, aliquoted, and stored at $-80^{\circ} \mathrm{C}$ before use.

Invasion Assays: The human breast carcinoma cell line MDA-MB231 or the mouse mammary carcinoma cell line 4T1 was used for all in vitro experiments. Cells were routinely cultured on tissue culture polystyrene flasks in RPMI media supplemented with 10\% FBS, 1\% penicillin-streptomycin solution, $1 \%$ nonessential amino acids, and $1 \%$ sodium pyruvate (Life Technologies). Media were exchanged every other day. Once $\approx 80 \%$ confluent, cells were harvested with TrypLE Express (Life Technologies) solution and counted using a Trypan blue stain (Sigma Aldrich) and a Cell Countess automated hemocytometer (Life Technologies). All cells were cultured in a humidified $5 \% \mathrm{CO}_{2}$ incubator at $37^{\circ} \mathrm{C}$.

For all invasion assays, confluent cultures of MDA-MB-231 or 4T1 cells were serum starved overnight in serum-free RPMI supplemented with $1 \%$ penicillin-streptomycin solution, $1 \%$ nonessential amino acids, and $1 \%$ sodium pyruvate prior to harvesting. Invasion assays were performed using Matrigel-coated transwell chambers with $8 \mu \mathrm{m}$ pores (BD Biosciences). The membranes were hydrated with serum-free media for $1 \mathrm{~h}$ before plating cells. Serum-free cell suspensions were prepared and plated in transwell inserts at a density of 50,000 cells per insert. Inserts were then placed in unconditioned RPMI media, mock CD $45^{+}$ conditioned media, or scaffold $\mathrm{CD}_{4} 5^{+}$conditioned media supplemented with $2.0 \%$ FBS. Transwell inserts with cells were incubated for $24 \mathrm{~h}$ in a humidified $5 \% \mathrm{CO}_{2}$ incubator at $37{ }^{\circ} \mathrm{C}$. After the incubation period, the cells on the top of the membrane were scraped away using a cotton swab soaked in PBS. Cells were fixed and stained in a $0.5 \% \mathrm{w} / \mathrm{v}$ crystal violet solution using a $60 \% \mathrm{EtOH} / 40 \%$ PBS solvent. Cells were imaged directly on the membrane with a Nikon Eclipse inverted microscope, and imaged at 10x. Four images per well were captured $(n=4)$ and cell numbers were quantified using Image). All experiments were performed in triplicate and pooled together $(n \geq 12)$. Statistical analysis was performed in GraphPad Prism, using one-way analysis of variance (ANOVA) with Bonferroni testing for multiple comparisons.

Quantitative RT-PCR Sample Preparation and Analysis: Tumors were isolated from $n=6$ scaffold and $n=6$ mock mice as previously described. A minimum of 100,000 cells of each subtype were sorted and collected in TRIzol reagent (Invitrogen) and RNA was isolated as per the manufacturer's recommendations. Purified RNA was quantified via NanoDrop 2000 (Thermo Scientific) and reverse transcribed using the iScript cDNA synthesis kit (BioRad). Samples were then prepared in technical duplicate with six biological replicates using the QuantiTect SYBR Green PCR Kit (Qiagen) and gene probes (Tables S2 and S7, Supporting Information). Quantification was performed using an $A B I$ $7900 \mathrm{HT}$ instrument (Applied Biosystems). Data were analyzed in Excel as previously described ${ }^{[11]}$ with nondetects excluded from analysis and a reference $\mathrm{Cq}$ (defined as the mean of three reference genes, ActB, $G A P D H$, and Rplpo) used to normalize the $\mathrm{Cq}$ values of each sample. Significance was determined using the Student's $t$-test.

Secretomics Sample Preparation, Analysis, and Validation: Secretomics analysis was performed as previously described. [14] For secretomics analysis, $\mathrm{CD}_{4} 5^{+}$cells collected via FACS were washed three times with media to ensure sufficient removal of FBS contamination from FACS collection media. Approximately $10^{5}$ live $\mathrm{CD}_{4} 5^{+}$cells were cultured in $500 \mu \mathrm{L}$ of serum-free media for $48 \mathrm{~h}$. Samples were passed through a $0.22 \mu \mathrm{m}$ filter and protein concentration was measured using a NanoDrop 1000 (Thermo Scientific). Samples were stored at $-80^{\circ} \mathrm{C}$ before use.

For each concentrated conditioned media sample (three biological replicates), $5 \mu \mathrm{g}$ of protein was solubilized by adding $8 \mathrm{~m}$ urea and incubating at $50{ }^{\circ} \mathrm{C}$ for $60 \mathrm{~min}$. Following denaturation, proteins were 
solubilized and reduced by adding $10 \times 10^{-3} \mathrm{M}$ dithiothreitol (DTT) (final concentration: $1 \times 10^{-3} \mathrm{M}$ ) and incubating at $50^{\circ} \mathrm{C}$ for $15 \mathrm{~min}$. After reduction, proteins were alkylated by adding $100 \times 10^{-3} \mathrm{M}$ iodoacetamide (final concentration: $10 \times 10^{-3} \mathrm{M}$ ) and incubated in the dark at room temperature for $15 \mathrm{~min}$. Protein samples were digested by diluting the $8 \mathrm{M}$ urea solution to $1 \mathrm{M}$ by adding $100 \times 10^{-3} \mathrm{M}$ ammonium bicarbonate and trypsin. The sample was digested at $37^{\circ} \mathrm{C}$ overnight. The digested samples were desalted using reverse phase $\mathrm{C} 18$ spin columns (Thermo Fisher Scientific). After desalting, the peptides were concentrated in vaccuo until dry. After drying, peptides were suspended in $5 \%$ acetonitrile and $0.1 \%$ formic acid. The samples were loaded directly onto a $15 \mathrm{~cm}$ long, $75 \times 10^{-6} \mathrm{M}$ reversed phase capillary column (ProteoPep II C18, $300 \AA, 5 \mu \mathrm{m}$ size, New Objective) and separated using a $200 \mathrm{~min}$ gradient from $5 \%$ acetonitrile to $100 \%$ acetonitrile on a Proxeon Easy n-LC II (Thermo Scientific). The peptides were eluted into an LTQ Orbitrap Velos mass spectrometer (Thermo Scientific) with electrospray

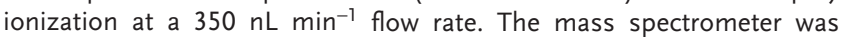
operated in data-dependent mode. For each MS1 precursor ion scan, the ten most intense ions were selected for fragmentation by collisioninduced dissociation. Additional parameters for mass spectrometry analysis included setting the resolution of MS1 at 60,000, the normalized collision energy at $35 \%$, the activation time at $10 \mathrm{~ms}$, and the isolation width at 1.5. Charge states +4 and higher were rejected.

The data were processed using Proteome Discoverer (version 1.4, Thermo Scientific) and searched using embedded SEQUEST HT search engine. The data were searched against a mouse reference proteome (September 2013, Uniprot). Additional search parameters were as follows: (i) enzyme specificity: trypsin, (ii) fixed modification: cysteine carbamidomethylation, (iii) variable modification: methionine oxidation and $\mathrm{N}$-terminal acetylation, (iv) precursor mass tolerance was $\pm 10 \mathrm{ppm}$, and (iv) fragment ion mass tolerance was $\pm 0.8 \mathrm{Da}$. All the spectra were searched against target/decoy databases and results were used to estimate the $q$ values with the Percolator algorithm embedded in Proteome discoverer 1.4. The peptide identification was considered valid at $q$ value $<0.1$ and was grouped for protein inference to satisfy the rule of parsimony. Further, each protein in the final identification list was considered valid if supported with a minimum of one unique peptide.

Proteins were quantified using spectral counting ${ }^{[52]}$ and normalized spectral abundance factors (NSAF). ${ }^{[53,54]}$ The NSAF normalization takes into consideration of the length of the protein, which may result into higher spectral count per protein. Initially, the total number of spectral counts (spc) per protein was divided by the peptide length $(L)$, and then divided by the sum $\left(\sum \mathrm{spc} / L\right)$ of all the values in the sample. Proteins were determined significantly changed with a $t$-test (significance level of $p<0.05$ ) and a log2 fold change greater than or equal to 1.5.

ELISAs were performed per the manufacturer's protocol. Conditioned media samples were directly added to CCL2 and decorin ELISA plates (Abcam) and absorbance at $450 \mathrm{~nm}$ was used to determine concentration using a standard curve.

CD45 $5^{+}$Conditioned Media TRACER Arrays: TRACER arrays were performed as previously described. ${ }^{[14,55]}$ Harvested MDA-MB-231 cells were diluted to a final concentration of 50 cells $\mu \mathrm{L}^{-1}$. About $400 \mu \mathrm{L}$ of this suspension was aliquoted into separate $1.5 \mathrm{~mL}$ Eppendorf tubes for viral infection. The aliquot was mixed with lentiviral vectors containing TF reporter constructs at a multiplicity of infection of approximately ten virions per cell. Cells and virus were mixed and plated at 2000 cells per well in a black, clear bottom, 384-well plate (Greiner Bio-One). Cells plated without virus infection served as negative controls for nonenzymatic DLuc degradation. A positive control consisting of a TA-FLuc reporter construct without any additional TF binding elements was used to determine basal promoter activity. Each TF reporter is represented with $n=4$ measurements per array plate, and arrays were repeated a total of six times. After infection, cells were incubated for $48 \mathrm{~h}$.

To measure TF activity, D-luciferin (DLuc, RR Labs, Inc.) diluted in the appropriate media (mock $\mathrm{CD} 45^{+}$or scaffold $\mathrm{CD} 45^{+}$) was added to wells in excess at a final concentration of $2 \times 10^{-3} \mathrm{M}$. After a $45 \mathrm{~min}$ incubation period with the DLuc, the luminescence was quantified using an IVIS Lumina LTE imaging system (Caliper Life Sciences). Cells plated without virus infection served as negative controls for nonenzymatic DLuc degradation. A positive control consisted of a TA-FLuc reporter construct without any additional TF-binding elements, which was used to determine basal promoter activity. All luminescence readings, measured in photon flux (photons per second), were normalized to the TA luminescence. On Day 0 , cells were treated with either mock or scaffold $\mathrm{CD}_{4} 5^{+}$media containing $2 \times 10^{-3} \mathrm{M}$ of DLuc and $10 \% \mathrm{FBS}$. Bioluminescence imaging was conducted every $2 \mathrm{~h}$, and five reads were taken in $1 \mathrm{~d}$. Each TF reporter was represented with $n=4$ measurements per array plate, and arrays were repeated three times.

Initial methodology to normalize and determine statistical significance was slightly modified. ${ }^{[56]}$ Array data were log2 transformed and filtered to eliminate all intensities below background $(p<0.05)$. The background was defined as the mean measured intensity in noninfected cells subject to the same treatment at the same time and plate. At each time point, the TA control reporter and the control condition were used to normalize reporter activity to calculate the fold change in TF activity of cells cultured in scaffold $\mathrm{CD} 45^{+}$media relative to mock $\mathrm{CD} 45^{+}$media. Normalized values that were identified to be outliers $(p<0.003)$ for each reporter were removed.

Normalized log2 TF activity fold change of MDA-MB-231 cells cultured in scaffold versus mock $\mathrm{CD} 45^{+}$media was compared using the limma package in R. ${ }^{[57]} \mathrm{A}$ linear model was fit to the normalized log2 values for each TF and was used to generate estimated coefficients and squared errors (SEs) for each time point of the compared samples. The estimated coefficients and SEs were then used to compute moderated $t$-statistics, moderated F-statistics, and log-odds of differential expression. FDR was used to correct for multiple comparisons. TFs identified to be differentially active had an adjusted $p$-value of less than 0.05 .

RNAseq Preparation, Library Construction, and Sequencing: RNA samples were obtained from FACS collected tdTomato tumor cells $(n=3$ mock and $n=3$ scaffold) using an RNeasy MiniKit (Qiagen) according to the manufacturer's protocol. RNA concentration was quantified using a NanoDrop 1000, and RNA samples were stored in $-80^{\circ} \mathrm{C}$ until further use. RNA quality was assessed using an Agilent 2100 Bioanalyzer.

The Beijing Genomics Institute performed the library construction (100 bp, paired end) and sequencing. The total RNA samples were enriched using oligo(dT) magnetic beads. Mixed with the fragmentation buffer, the mRNA was fragmented into short fragments of about $200 \mathrm{bp}$. Then, the first strand of cDNA was synthesized using random hexamerprimer. Buffer, dNTPs, RNase $\mathrm{H}$, and DNA polymerase I were added to synthesize the second strand. The double stranded cDNA was purified with magnetic beads. End reparation and 3 '-end single nucleotide $A$ (adenine) addition were then performed. Finally, sequencing adaptors were ligated to the fragments. The fragments were enriched by $P C R$ amplification. During the QC step, Agilent 2100 Bioanalyzer and ABI StepOnePlus Real-Time PCR System were used to qualify and quantify the sample libraries. Finally, the library products were sequenced on the Illumina HiSeq2000.

Transcriptome Analysis: The quality of DNA reads, in fastq format, was evaluated using FastQC. Adapters were removed and reads of poor quality were filtered. The data were processed largely following the procedure previously described. ${ }^{[58]}$ Briefly, the reads were aligned to the Homo sapiens genome (hg19) using TopHat (v2.0.8b). Subsequently, the aligned reads, in conjunction with a gene annotation file for hgl9 obtained from the UCSC website, were used to determine the expression of known genes using Cufflinks (v2.1.1). The individual transcript files generated by Cufflinks for each sample were merged into a single gene annotation file, which was then used to perform a differential expression analysis with the Cufflinks routine, cuffdiff. Differential expression was determined by cuffdiff using a $p$-value cutoff value of $0.01 .{ }^{[58]}$ The results of the differential expression analysis were processed with cummeRbund. Gene ontology and pathway analysis was performed on upregulated and downregulated genes separately with significance threshold of $p<0.01$ and FDR $<0.1$ using Metascape. [59]

Statistical Analysis: Data were shown as mean \pm standard error (SEM) unless otherwise noted. Significance was claimed for $p$-values less 
than 0.05 , as determined using unpaired Student's $t$-tests for single comparisons or one-way ANOVA with Bonferroni testing for multiple comparisons unless otherwise noted. Statistical analysis was performed in GraphPad Prism unless otherwise noted. Sample sizes and data preprocessing differed by experimental methodology and are discussed in the respective experimental subsections and figure legends.

\section{Supporting Information}

Supporting Information is available from the Wiley Online Library or from the author.

\section{Acknowledgements}

B.A.A. and R.M.H. contributed equally to this work. B.A.A., R.M.H, and L.D.S. designed the experiments; B.A.A., R.M.H., G.G.B., S.M.A., S.S.R, R.S.O., and Y.Z. performed experiments; B.A.A. and R.M.H. collected data, performed data analyses, and prepared figures; J.T.D. analyzed TRACER results; D.N. analyzed secretomics results; M.J.S. analyzed RNAseq results; I.S.J. edited and advised on the manuscript; B.A.A., R.M.H. and L.D.S. wrote and edited the manuscript. The Tumor Biology Core at Northwestern University provided MDA-MB-231BR and 4T1 cells for the study. The Northwestern University Proteomics Core Facility supported secretomics work and analysis. The Simpson Querrey Institute Equipment Core provided access to microscopy equipment. Flow cytometry work was supported by the Northwestern University Robert H. Lurie Comprehensive Cancer Center Flow Cytometry Core Facility and the University of Michigan Flow Cytometry Core. The authors thank Katie Aguado for illustrating the mouse image in the schematics. Financial support for this work was provided by the National Institutes of Health and the National Cancer Institute (R01 CA173745). B.A.A. and G.G.B. acknowledge the support of a National Science Foundation Graduate Research Fellowship.

\section{Conflict of Interest}

The authors declare no conflict of interest.

\section{Keywords}

biomaterial, immunomodulation, metastasis, pre-metastatic niche, tumor microenvironment

Received: July 28, 2017

Revised: January 28, 2018

Published online: March 9, 2018

[1] H. Peinado, M. Aleckovic, S. Lavotshkin, I. Matei, B. Costa-Silva, G. Moreno-Bueno, M. Hergueta-Redondo, C. Williams, G. Garcia-Santos, C. Ghajar, A. Nitadori-Hoshino, C. Hoffman, K. Badal, B. A. Garcia, M. K. Callahan, J. Yuan, V. R. Martins, J. Skog, R. N. Kaplan, M. S. Brady, J. D. Wolchok, P. B. Chapman, Y. Kang, J. Bromberg, D. Lyden, Nat. Med. 2012, 18, 883.

[2] T. Kitamura, B. Z. Qian, J. W. Pollard, Nat. Rev. Immunol. 2015, 15, 73.

[3] R. A. Franklin, W. Liao, A. Sarkar, M. V. Kim, M. R. Bivona, K. Liu, E. G. Pamer, M. O. Li, Science 2014, 344, 921.

[4] S. C. Chafe, Y. Lou, J. Sceneay, M. Vallejo, M. J. Hamilton, P. C. McDonald, K. L. Bennewith, A. Moller, S. Dedhar, Cancer Res. 2015, 75, 996.
[5] D. I. Gabrilovich, S. Nagaraj, Nat. Rev. Immunol. 2009, 9, 162.

[6] S. Hiratsuka, A. Watanabe, H. Aburatani, Y. Maru, Nat. Cell Biol. 2006, 8, 1369.

[7] H. H. Yan, M. Pickup, Y. Pang, A. E. Gorska, Z. Li, A. Chytil, Y. Geng, J. W. Gray, H. L. Moses, L. Yang, Cancer Res. 2010, 70, 6139.

[8] R. N. Kaplan, R. D. Riba, S. Zacharoulis, A. H. Bramley, L. Vincent, C. Costa, D. D. MacDonald, D. K. Jin, K. Shido, S. A. Kerns, Z. Zhu, D. Hicklin, Y. Wu, J. L. Port, N. Altorki, E. R. Port, D. Ruggero, S. V. Shmelkov, K. K. Jensen, S. Rafii, D. Lyden, Nature 2005, 438, 820.

[9] M. S. Sosa, P. Bragado, J. A. Aguirre-Ghiso, Nat. Rev. Cancer 2014, $14,611$.

[10] F. Bersani, J. Lee, M. Yu, R. Morris, R. Desai, S. Ramaswamy, M. Toner, D. A. Haber, B. Parekkadan, Cancer Res. 2014, 74, 7229.

[11] J. Lee, M. Li, J. Milwid, J. Dunham, C. Vinegoni, R. Gorbatov, Y. Iwamoto, F. Wang, K. Shen, K. Hatfield, M. Enger, S. Shafiee, E. McCormack, B. L. Ebert, R. Weissleder, M. L. Yarmush, B. Parekkadan, Proc. Natl. Acad. Sci. USA 2012, 109, 19638

[12] F. P. Seib, J. E. Berry, Y. Shiozawa, R. S. Taichman, D. L. Kaplan, Biomaterials 2015, 51, 313.

[13] B. A. Aguado, J. R. Caffe, D. Nanavati, S. S. Rao, G. G. Bushnell, S. M. Azarin, L. D. Shea, Acta Biomater. 2016, 33, 13.

[14] B. A. Aguado, J. J. Wu, S. M. Azarin, D. Nanavati, S. S. Rao, G. G. Bushnell, C. B. Medicherla, L. D. Shea, Sci. Rep. 2015, 5, 17566.

[15] S. M. Azarin, J. Yi, R. M. Gower, B. A. Aguado, M. E. Sullivan, A. G. Goodman, E. J. Jiang, S. S. Rao, Y. Ren, S. L. Tucker, V. Backman, J. S. Jeruss, L. D. Shea, Nat. Commun. 2015, 6, 8094.

[16] S. S. Rao, G. G. Bushnell, S. M. Azarin, G. Spicer, B. A. Aguado, J. R. Stoehr, E. J. Jiang, V. Backman, L. D. Shea, J. S. Jeruss, Cancer Res. 2016, 76, 5209.

[17] B. A. Aguado, G. G. Bushnell, S. S. Rao, J. S. Jeruss, L. D. Shea, Nat. Biomed. Eng. 2017, 1, pii: 0077.

[18] A. de la Fuente, L. Alonso-Alconada, C. Costa, J. Cueva, T. Garcia-Caballero, R. Lopez-Lopez, M. Abal, J. Natl. Cancer Inst. 2015, 107, pii: djv184.

[19] R. M. Gower, R. M. Boehler, S. M. Azarin, C. F. Ricci, J. N. Leonard, L. D. Shea, Biomaterials 2014, 35, 2024.

[20] B. M. Holzapfel, J. C. Reichert, J. T. Schantz, U. Gbureck, L. Rackwitz, U. Noth, F. Jakob, M. Rudert, J. Groll, D. W. Hutmacher, Adv. Drug Delivery Rev. 2013, 65, 581.

[21] N. B. Hao, M. H. Lu, Y. H. Fan, Y. L. Cao, Z. R. Zhang, S. M. Yang, Clin. Dev. Immunol. 2012, 2012, 948098.

[22] D. W. Infanger, M. E. Lynch, C. Fischbach, Annu. Rev. Biomed. Eng. 2013, 15, 29

[23] H. A. Smith, Y. Kang, J. Mol. Med. 2013, 91, 411.

[24] T. Chanmee, P. Ontong, K. Konno, N. Itano, Cancers 2014, 6, 1670.

[25] T. Lanca, B. Silva-Santos, Oncoimmunology 2012, 1, 717.

[26] M. A. Gubbiotti, S. D. Vallet, S. Ricard-Blum, R. V. lozzo, Matrix Biol. 2016, 55, 7.

[27] B. Ell, Y. Kang, Trends Cell Biol. 2013, 23, 603.

[28] S. Julien, I. Puig, E. Caretti, J. Bonaventure, L. Nelles, F. van Roy, C. Dargemont, A. Garcia de Herreros, A. Bellacosa, L. Larue, Oncogene 2007, 26, 7445.

[29] Y. Li, Q. Ke, Y. G. Shao, G. Zhu, Y. S. Li, N. X. Geng, F. Jin, F. Li, Oncotarget 2015, 6, 4345.

[30] S. Medjkane, C. Perez-Sanchez, C. Gaggioli, E. Sahai, R. Treisman, Nat. Cell Biol. 2009, 11, 257.

[31] F. U. Weiss, I. J. Marques, J. M. Woltering, D. H. Vlecken, A. Aghdassi, L. I. Partecke, C. D. Heidecke, M. M. Lerch, C. P. Bagowski, Gastroenterology 2009, 137, 2136.

[32] K. Movahedi, D. Laoui, C. Gysemans, M. Baeten, G. Stange, J. Van den Bossche, M. Mack, D. Pipeleers, P. In't Veld, P. De Baetselier, J. A. Van Ginderachter, Cancer Res. 2010, 70, 5728 .

[33] B. Z. Qian, J. Li, H. Zhang, T. Kitamura, J. Zhang, L. R. Campion, E. A. Kaiser, L. A. Snyder, J. W. Pollard, Nature 2011, 475, 222. 
[34] W. B. Fang, I. Jokar, A. Zou, D. Lambert, P. Dendukuri, N. Cheng, J. Biol. Chem. 2012, 287, 36593.

[35] C. Kudo-Saito, H. Shirako, M. Ohike, N. Tsukamoto, Y. Kawakami, Clin. Exp. Metastasis 2013, 30, 393.

[36] K. Araki, H. Wakabayashi, K. Shintani, J. Morikawa, A. Matsumine, K. Kusuzaki, A. Sudo, A. Uchida, Oncology 2009, 77, 92.

[37] C. C. Reed, A. Waterhouse, S. Kirby, P. Kay, R. T. Owens, D. J. McQuillan, R. V. Iozzo, Oncogene 2005, 24, 1104.

[38] D. D. Sofeu Feugaing, M. Gotte, M. Viola, Eur. J. Cell Biol. 2013, 92, 1.

[39] C. Soria-Valles, A. Gutierrez-Fernandez, M. Guiu, B. Mari, A. Fueyo, R. R. Gomis, C. Lopez-Otin, Oncogene 2014, 33, 3054.

[40] Y. Wu, J. Deng, P. G. Rychahou, S. Qiu, B. M. Evers, B. P. Zhou, Cancer Cell 2009, 15, 416.

[41] G. L. Huang, Q. Luo, G. Rui, W. Zhang, Q. Y. Zhang, Q. X. Chen, D. Y. Shen, Mol. Cell. Biol. 2013, 33, 3416.

[42] T. Neill, L. Schaefer, R. V. Iozzo, Adv. Drug Delivery Rev. 2016, 97, 174.

[43] M. M. Chaturvedi, B. Sung, V. R. Yadav, R. Kannappan, B. B. Aggarwal, Oncogene 2011, 30, 1615.

[44] G. Franzoso, L. Carlson, K. Brown, M. B. Daucher, P. Bressler, U. Siebenlist, EMBO J. 1996, 15, 3403.

[45] J. Condeelis, J. W. Pollard, Cell 2006, 124, 263.

[46] J. W. Pollard, J. Leukoc. Biol. 2008, 84, 623.

[47] B. Z. Qian, J. W. Pollard, Cell 2010, 141, 39

[48] A. Sica, A. Saccani, B. Bottazzi, S. Bernasconi, P. Allavena, B. Gaetano, F. Fei, G. LaRosa, C. Scotton, F. Balkwill, A. Mantovani, J. Immunol. 2000, 164, 733.
[49] B. A. Aguado, J. C. Grim, A. M. Rosales, J. J. Watson-Capps, K. S. Anseth, Sci. Transl. Med. 2018, 10, eaam8645.

[50] E. Dondossola, B. M. Holzapfel, S. Alexander, S. Filippini, D. W. Hutmacher, P. Friedl, Nat. Biomed. Eng. 2016, 1, 0007.

[51] K. J. Livak, T. D. Schmittgen, Methods 2001, 25, 402.

[52] H. Liu, R. G. Sadygov, J. R. Yates3rd, Anal. Chem. 2004, 76, 4193.

[53] R. Usaite, J. Wohlschlegel, J. D. Venable, S. K. Park, J. Nielsen, L. Olsson, J. R. Yates lii, J. Proteome Res. 2008, 7, 266.

[54] B. Zybailov, A. L. Mosley, M. E. Sardiu, M. K. Coleman, L. Florens, M. P. Washburn, J. Proteome Res. 2006, 5, 2339.

[55] A. D. Dubash, C. Y. Kam, B. A. Aguado, D. M. Patel, M. Delmar, L. D. Shea, K. J. Green, J. Cell Biol. 2016, 212, 425.

[56] M. S. Weiss, B. Penalver Bernabe, S. Shin, S. Asztalos, S. J. Dubbury, M. D. Mui, A. D. Bellis, D. Bluver, D. A. Tonetti, J. Saez-Rodriguez, L. J. Broadbelt, J. S. Jeruss, L. D. Shea, Integr. Biol. 2014, 6, 1170.

[57] G. K. Smyth, J. Michaud, H. S. Scott, Bioinformatics 2005, 21, 2067.

[58] C. Trapnell, A. Roberts, L. Goff, G. Pertea, D. Kim, D. R. Kelley, H. Pimentel, S. L. Salzberg, J. L. Rinn, L. Pachter, Nat. Protoc. 2012, 7, 562.

[59] S. Tripathi, M. O. Pohl, Y. Zhou, A. Rodriguez-Frandsen, G. Wang, D. A. Stein, H. M. Moulton, P. Dejesus, J. Che, L. C. Mulder, E. Yanguez, D. Andenmatten, L. Pache, B. Manicassamy, R. A. Albrecht, M. G. Gonzalez, Q. Nguyen, A. Brass, S. Elledge, M. White, S. Shapira, N. Hacohen, A. Karlas, T. F. Meyer, M. Shales, A. Gatorano, J. R. Johnson, G. Jang, T. Johnson, E. Verschueren, D. Sanders, N. Krogan, M. Shaw, R. Konig, S. Stertz, A. Garcia-Sastre, S. K. Chanda, Cell Host Microbe 2015, 18, 723. 